\title{
High sensitivity C-reactive protein and risk of migraine in a 11-year follow-up with data from the Nord-Trøndelag health surveys 2006-2008 and 2017-2019
}

Knut Hagen ${ }^{1,2^{*}}$ (D) Lars Jacob Stovner ${ }^{1,3}$ and John-Anker Zwart ${ }^{4,5}$

\begin{abstract}
Background: Several previous studies have reported a cross-sectional association between elevated high sensitivity C-reactive protein (hs-CRP) and migraine. The aim of this population-based follow-up study was to investigate the influence of hs-CRP at baseline on the risk of developing migraine 11 years later.

Methods: Data from the Nord-Trøndelag Health Study performed in 2006-2008 (baseline) and 2017-2019 were used. A total of 19,574 participants without migraine at baseline were divided into three groups based on hs-CRP levels ( $<3 \mathrm{mg} / \mathrm{L}, 3-9.99 \mathrm{mg} / \mathrm{L}$ and $10.00-20 \mathrm{mg} / \mathrm{L}$ ). Poisson regression was used to evaluate the associations between hs-CRP levels and risk ratios (RRs) of migraine, and precision of the estimates was assessed by $95 \%$ confidence interval (Cls).

Results: In the multi-adjusted model, increased risk of migraine (RR 1.46, 95\% Cl 1.05-2.04) was found in the highest hs-CRP levels group compared to the lowest group. In the group with the highest hs-CRP levels, a nearly three times higher risk of chronic migraine (RR 2.81,95\% Cl 1.12-7.06) was found, whereas no evident relationship was found between high hs-CRP level and risk of developing episodic migraine.

Conclusions: The main finding in this 11-year follow-up was that hs-CRP levels between 10.00-20.00 mg/L at baseline was associated with increased risk of chronic migraine.
\end{abstract}

Keywords: Migraine, Epidemiology, General population, Follow-up, Inflammation

\section{Introduction}

The pathophysiology of migraine is complex and not fully understood [1]. In the transition from episodic to chronic migraine, several mechanisms have been suggested to be involved, including a sterile inflammation

\footnotetext{
* Correspondence: knut.hagen@ntnu.no

${ }^{1}$ Department of Neuromedicine and Movement Science, Faculty of medicine and health sciences, Norwegian University of Science and Technology, 7489 Trondheim, Norway

${ }^{2}$ Clinical Research Unit Central Norway, St. Olavs University Hospital, Trondheim, Norway

Full list of author information is available at the end of the article
}

[1]. A non-specific marker of inflammation is high sensitivity C-reactive protein (hs-CRP).

A review published in 2014 of previous cross-sectional studies evaluating the association between hs-CRP and migraine concluded that most studies have found increased hs-CRP levels [2]. This was confirmed in two more recent Norwegian large-scale population-based studies $[3,4]$. However, a potential causal relationship between hs-CRP and migraine cannot be evaluated in crosssectional studies. For this, we need longitudinal studies, and to the best of our knowledge, no previous large-scale population-based follow-up studies have analyzed this. 
In the present study, we evaluated the influence of hsCRP on the risk of developing migraine in a 11-year follow-up. Based on previous knowledge, we hypothesized that elevated hs-CRP increased the risk of migraine.

\section{Methods}

\section{Study design}

This is a population-based historical cohort study. The influence of hs-CRP at baseline was evaluated on the risk of migraine 11 years later.

\section{The HUNT surveys}

The present study included data from the two last HUNT surveys conducted in Nord-Trøndelag County, Norway, in 2006-2008 (HUNT3) [5], and in 2017-2019 (HUNT4) [6]. The entire population of the NordTrøndelag County aged 20 years of age or more was invited to answer many health-related items in two different questionnaires (Q1 and Q2), including questions about headache, and also a clinical examination, including measurement of weight, height and blood pressure, and blood samples were also taken $[5,6]$.

\section{C-reactive protein}

Analyses of the blood samples for hs-CRP were done in almost all HUNT3 participants. The method has been described previously [4]. In brief, hs-CRP was analyzed at the Central Laboratory, Levanger Hospital, using Architect cSystem ci8200, by latex immunoassay method. The detection limit was $0.03 \mathrm{mg} / \mathrm{L}$, and samples without detectable hs-CRP were assigned this value. In the present study we divided the participants into three categories based on hs-CRP levels; normal (hs-CRP as $0-2.99 \mathrm{mg} / \mathrm{L}$ ), medium elevated (3.00$9.99 \mathrm{mg} / \mathrm{L})$, and high (10.00-20.00 mg/L). Participants with hs-CRP values $>20.00 \mathrm{mg} / \mathrm{L}$ at baseline, which probably indicate some acute or chronic disease [7], were excluded ( $n=527)$ (Fig. 1$)$.

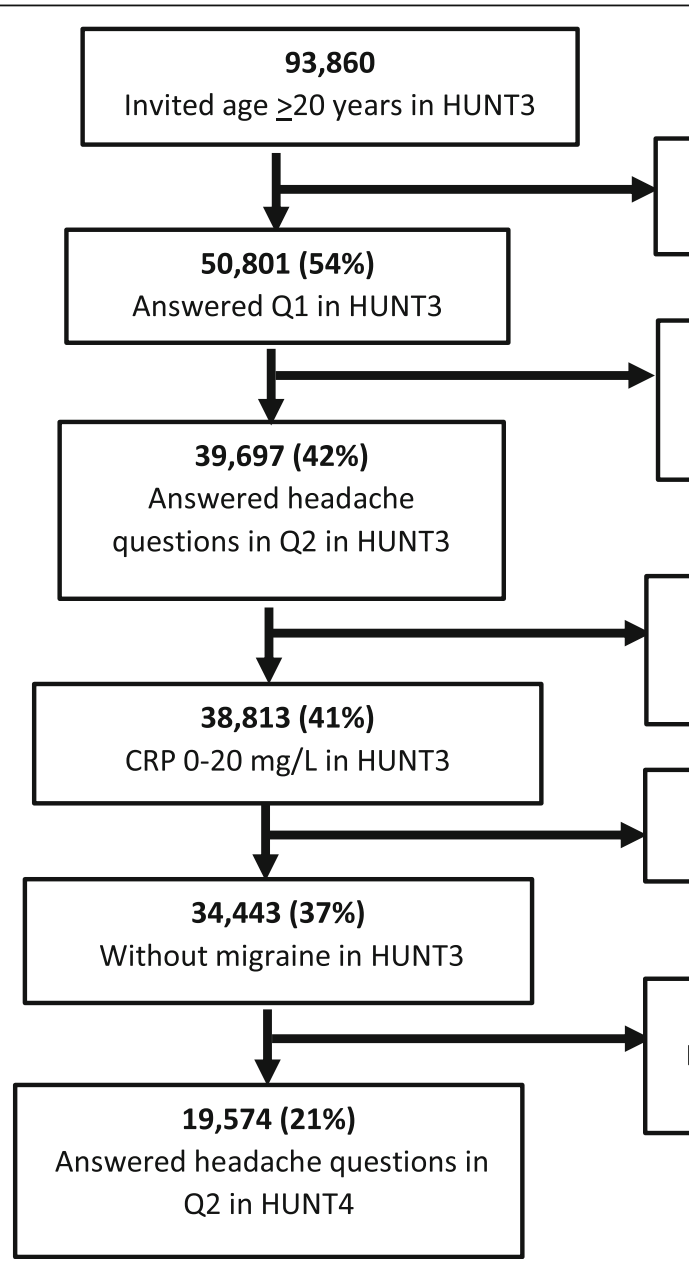

43,059

Non-participants

11,104

No information on headache

hs-CRP missing: 372

hs-CRP>20 mg/l: 527

4303

Migraine in HUNT3

Did not participate in HUNT4:10606

Did not answer Q2: 3890

Fig. 1 The flow of participants in the present study 


\section{Headache diagnoses}

HUNT3 and HUNT4 had 14 identical headache questions [6]. The initial screening question was "Have you suffered from headache during the last 12 months?", and those who responded "yes" answered 13 additional questions. A slight modification of the criteria of the International Classification of Headache Disorders, third edition (ICHD 3) [8] was used for diagnosing migraine [9]. As to the modifications of the criteria, individuals would fulfill the migraine criteria even if the attack lasted less than $4 \mathrm{~h}$, because they were not asked for untreated attacks in the question" How long does the headache usually last?" Migraine with aura was diagnosed in those who fulfilled the migraine criteria and answered "yes" to the question "Are the headaches usually characterized by or accompanied by visual disturbance before or during onset (zigzag lines, flickering/flashing light, blurred vision). Chronic migraine was diagnosed in those who fulfilled the criteria of migraine and reported headache $\geq 15$ days/month [6].

\section{Validity of headache diagnosis}

We have previously reported the validity of the questionnaire-based headache diagnoses in HUNT3 [9], and HUNT4 [10]. Merged data of HUNT3 $(n=293)$ and HUNT4 $(n=232)$ gave the following results: for migraine, the sensitivity was $54 \%$ and specificity $95 \%$ (kappa value $0.52,95 \%$ CI $0.47-0.57$ ) and for migraine with aura, the sensitivity was $39 \%$ and specificity $95 \%$ (kappa value 0.34, 95\% CI 0.30-0.38) [6]. For chronic headache (headache $\geq 15$ days/month, included chronic migraine, chronic tension-type headache and medication overuse headache), the sensitivity was $58 \%$ and specificity $99 \%$ (kappa value 0.62 , 95\% CI $0.50-0.74$ ).

\section{Study population}

In HUNT3, 50,803 persons (54\%) participated out of 93, 860 invited (Fig. 1). Among these, 39,697 (42\% of all invited) answered the headache questions, and 38,813 (41\%) had measured hs-CRP and had values between 0 and $20.00 \mathrm{mg} / \mathrm{l}$. Among these, 4303 (11.1\%) with migraine in HUNT3 were eliminated. Thus, 34, 443 (37\%) were without migraine in HUNT3 and constituted the population at risk of developing migraine in HUNT4. A total of 19,574 persons (11,018 women and 8559 men) participated in both HUNT3 and HUNT4 and had answered the headache questions in HUNT4 (Fig. 1).

\section{Potential confounders}

The selection of potential confounders was based on previous literature [11-13]. We evaluated the following potential confounders: Age (10-years categories), gender; duration of education $(\leq 9,10-12$, and $\geq 13$ years), body mass index (BMI) $\left(<25,25.0-29.9\right.$, and $\left.\geq 30 \mathrm{~kg} / \mathrm{m}^{2}\right)$; smoking (current, previous, and never); alcohol consumption during the last year (never, $<2$ times/week, $\geq 2$ times/week); total Hospital Anxiety and Depression Scale $(0-16, \geq 17)$, headache suffering (yes/no); selfreported diabetes (yes/no); self-reported stroke (yes/no); and self-reported hypertension (yes/no).

\section{Ethics}

This study was approved by the Regional Committee for Medical and Health Research Ethics, the Faculty of medicine, mailbox 8905,7491 Trondheim. The approval number was \#2018/2422/Rek Midt. The participants have given written informed consent.

\section{Statistical analysis}

A modified Poisson regression with a robust error variance was used to estimate the association between hs-CRP at baseline and risk ratios (RRs) of migraine. Precision of RRs were assessed by $95 \%$ confidence intervals (CIs). We present results for three different statistical models separated by number of confounders included; model 1 (age and sex), model 2 (age, sex and BMI), and model 3 (multi-adjusted model testing for all other factors). In model 3 we excluded factors if they did not change RR when evaluating each factor separately or when including several factors grouped together (i.e. self-reported diabetes, stroke, and hypertension). Subjects with missing data on confounding factors (numbers reported in Table 1) were included in the analysis to reduce the impact of possible bias. Analyses were performed with the IBM SPSS version 26 (SPSS, Chicago, Illinois, USA).

\section{Results}

Baseline characteristics of the population at risk related to hs-CRP categories in HUNT3 are given in Table 1. As demonstrated, the large group of individuals $(n=15,841)$ with hs-CRP levels $<3.00 \mathrm{mg} / \mathrm{l}$ were younger and more likely to have education $\geq 13$ years, and less likely to report diseases or complaints than those with hs-CRP levels $\geq 3.00$.

\section{Development of migraine at follow-up}

In the population at risk $(n=19,574), 766(3.9 \%)$ fulfilled the criteria of migraine at follow-up in HUNT4, giving an incidence of 3.6 per 1000 person-years. A total of 354 (1.8\%) had migraine with aura, $412(2.1 \%)$ migraine without aura, $711(3.6 \%)$ had episodic migraine) and 55 (0.3\%) chronic migraine.

\section{Risk of migraine}

In the analyses adjusting for age and gender, participants with hs-CRP levels between $10.00-20.00 \mathrm{mg} / \mathrm{l}$ had increased risk of developing migraine $(\mathrm{RR}=1.53,95 \% \mathrm{CI}$ 
Table 1 Characteristics of participants $(n=19,574)$ at baseline in HUNT3 related to categories of high sensitivity C-reactive protein (hs-CRP)

\begin{tabular}{|c|c|c|c|}
\hline & \multicolumn{3}{|c|}{ Hs- CRP categories } \\
\hline & $<3 \mathrm{mg} / \mathrm{L}$ & $3.0-9.99$ & $10-20 \mathrm{mg} / \mathrm{L}$ \\
\hline Participants, n & 15,841 & 3253 & 480 \\
\hline Women (\%) & 54.8 & 62.2 & 63.8 \\
\hline Mean age, years (SD) & $52.8(13)$ & $54.6(14)$ & $53.9(15)$ \\
\hline$\geq 13$ years of education (\%) & 38.0 & 31.3 & 31.1 \\
\hline Current smoking, $\mathrm{n}(\%)$ (missing = 416) & 12.5 & 18.4 & 18.5 \\
\hline Mean $\mathrm{BMl}, \mathrm{kg} / \mathrm{m}^{2}(\mathrm{SD})$ (missing $=23$ ) & $26.6(4.2)$ & $29.3(4.9)$ & $29.4(5.5)$ \\
\hline Total HADS score (missing = 184) & $6.8(3.8)$ & $7.1(5.4)$ & $7.0(5.2)$ \\
\hline Alcohol abstainers during last year $(\%)($ missing $=341)$ & 6.3 & 7.6 & 8.9 \\
\hline Self-reported hypertension, n (\%) & 17.8 & 27.2 & 29.4 \\
\hline Self-reported stroke (\%) & 1.7 & 2.3 & 2.3 \\
\hline Self-reported diabetes mellitus, n (\%) & 3.4 & 5.5 & 6.2 \\
\hline Headache (\%) & 29.3 & 31.0 & 31.5 \\
\hline
\end{tabular}

HADS ospital Anxiety and Depression Scale, BMI body mass index

$1.10-2.14)$, migraine with aura $(\mathrm{RR}=1.67,05 \% \mathrm{CI} 1.01-$ 2.76), and chronic migraine $(\mathrm{RR}=3.43$, 95\% CI $1.38-$ 8.52) (Table 2). The multi-adjusted analyses slightly modified the risk ratio, being 1.46 (95\% CI 1.05-2.04) for migraine and 1.57 (95\% CI 0.95-2.59) for migraine with aura (Table 2). Participants with highest hs-CRP levels $(10.00-20.00 \mathrm{mg} / \mathrm{l})$ at baseline had nearly three times increased risk $(\mathrm{RR}=2.81,95 \% \mathrm{CI} 1.12-7.06)$ of developing chronic migraine in HUNT4 compared to persons with normal hs-CRP (Table 2). For episodic migraine, no evident increased risk was found (RR 1.35, 95\% CI 0.94-1.94). No relationship was found between
hs-CRP level between $3.00-9.99 \mathrm{mg} / \mathrm{l}$ and risk of migraine (Table 2).

\section{Discussion}

In this population-based 11-year follow-up study the main finding was an increased risk of chronic migraine in participants with high hs-CRP levels (10.00-20.00 mg/ l) at baseline.

\section{Comparison with other studies}

Most previous migraine studies focusing on hs-CRP have been clinical-based with relatively low number of

Table 2 Risk of migraine in HUNT4 based on categories of high sensitivity C-reactive protein (hs-CRP) in HUNT3 evaluated by poisson regression with 95\% confidence interval

\begin{tabular}{|c|c|c|c|c|c|c|}
\hline $\begin{array}{l}\text { Hs-CRP (mg/ } \\
\text { L) }\end{array}$ & Number & $\begin{array}{l}\text { Migraine (overall) } \\
\text { RR ( } 95 \% \mathrm{Cl})\end{array}$ & $\begin{array}{l}\text { Migraine with aura } \\
\text { RR }(95 \% \mathrm{Cl})\end{array}$ & $\begin{array}{l}\text { Migraine without aura } \\
\text { RR }(95 \% \text { Cl) }\end{array}$ & $\begin{array}{l}\text { Episodic migraine } \\
\text { RR }(95 \% \mathrm{Cl})\end{array}$ & $\begin{array}{l}\text { Chronic migraine } \\
\text { RR }(95 \% \mathrm{Cl}) \\
\end{array}$ \\
\hline \multicolumn{7}{|c|}{ Model 1 (Adjusted for age and gender) } \\
\hline$<3.0$ & 15,841 & 1.00 & 1.00 & 1.00 & 1.00 & 1.00 \\
\hline $3.00-9.99$ & 3253 & $1.03(0.86-1.24)$ & $1.00(0.76-1.33)$ & $1.06(0.82-1.36)$ & $1.05(0.87-1.28)$ & $0.76(0.35-1.66)$ \\
\hline $10.00-20.00$ & 480 & $1.53(1.10-2.14)$ & $1.67(1.01-2.76)$ & $1.50(0.93-2.42)$ & $1.41(0.98-2.04)$ & $3.43(1.38-8.52)$ \\
\hline \multicolumn{7}{|c|}{ Model 2 (Adjusted for age, gender and body mass index) } \\
\hline$\leq 2.99$ & 15,841 & 1.00 & 1.00 & 1.00 & 1.00 & 1.00 \\
\hline $3.00-9.99$ & 3253 & $0.98(0.81-1.18)$ & $0.96(0.72-1.29)$ & $1.00(0.77-1.29)$ & $1.00(0.82-1.22)$ & $0.71(0.33-1.54)$ \\
\hline $10.00-20.00$ & 480 & $1.44(1.03-2.03)$ & $1.60(0.95-2.66)$ & $1.38(0.86-2.24)$ & $1.32(0.91-1.92)$ & $3.36(1.29-8.28)$ \\
\hline \multicolumn{7}{|c|}{ Model 3 (Multi-adjusted model ${ }^{\mathrm{a}}$ ) } \\
\hline$\leq 2.99$ & 15,841 & 1.00 & 1.00 & 1.00 & 1.00 & 1.00 \\
\hline $3.00-9.99$ & 3253 & $1.00(0.74-1.35)$ & $0.96(0.73-1.27)$ & $1.02(0.80-1.30)$ & $1.01(0.84-1.21)$ & $0.71(0.32-1.56)$ \\
\hline 10.00-20.00 & 480 & $1.46(1.05-2.04)$ & $1.57(0.95-2.59)$ & $1.44(0.90-2.32)$ & $1.35(0.94-1.94)$ & $2.81(1.12-7.06)$ \\
\hline
\end{tabular}

${ }^{a}$ Multi-adjusted model: Adjusted for age, sex, body mass index, smoking, education level, alcohol use, headache status and Hospital Anxiety and Depression Scale score 
participants [7]. For example, no association between CRP and migraine was found in a case-control study of 59 participants [14]. Furthermore, no relationship between hs-CRP and headache frequency was reported in a case-control study including 216 migraineurs and 216 controls [15]. Among more recently performed crosssectional large-scale population-based studies, our main results are in accordance with the results from Troms $\varnothing$ in Northern Norway, including 20,486 participants, reporting an association between elevated hs-CRP for migraine $\geq 7$ days/month (OR 1.22, 95\% CI 1.01-1.46), but not for migraine less than 7 days/month [3]. Furthermore, in cross-sectional data from HUNT3 including 38, 807 participants, we found the strongest association between elevated hs-CRP for chronic migraine (OR 1.62, 95\% CI 1.21-2.17), but no clear association for migraine less than 7 days/month [4].

During the 11-year follow-up, the incidence of migraine was 3.6 per 1000 person-year. In comparison, a much higher incidence of migraine (8.1 per 1000 person-years) was found in a 12-years' follow-up in Denmark [16]. The reason for the much lower incidence of migraine in the present study is unclear. However, it may in part be explained by the difference in age of population at risk, being 25-64 years in the Danish study and $20-90$ years in the present study, and partly because the prevalence of migraine in Denmark increased from $11 \%$ to $15 \%$ from 1989 to 2001 [17], whereas the corresponding prevalence decreased from $12.0 \%$ to $11.1 \%$ from HUNT3 to HUNT4 [6].

\section{Interpretation}

The main result in the present 11-year follow-up was that high hs-CRP was associated with increased risk of chronic migraine. This is of relevance in the question of inflammation as an involved mechanism in the transitation from episodic to chronic migraine [1]. One may suggest that an inflammatory response, for which elevated hs-CRP is a marker, may have an impact on peripheral and/or central sensitization, which also may be important mechanisms in the transition from episodic to chronic migraine [1]. Accordingly, it has previously been demonstrated that hs-CRP is related to general pain sensitivity $[18,19]$.

\section{Strengths and limitations of the study}

The major strengths of this study are the longitudinal population-based cohort design with many participants, a wide age range, and the use of validated diagnoses of headache $[10,11]$. In the multivariate analyses, many potential confounding factors were available. However, to avoid over-adjustment bias [20], we adjusted only for the most established confounding factors in epidemiological studies. However, the possibility of residual confounding by an unrecognized factor cannot be ruled out.

Several study limitations should also be considered. Firstly, we have no information about potential risk factors of migraine that may have appeared during the follow-up period before HUNT4. Secondly, generalization of the results to the entire population must be made with some caution, since only $57 \%$ in the population at risk in HUNT3 were included in the present study $(21 \%$ of the invited population in HUNT3), and we cannot be certain that loss to followup was random. Thirdly, although the validity of headache $\geq 15$ days/month was good, it should be highlighted that only one person had chronic migraine among participants in the validation studies $[9,10)$. Thus, the validity of the questionnaire-based diagnosis of chronic migraine could not be reported. Finally, very few (55 participants) of the population at risk developed chronic migraine in HUNT4, giving a wide confidence interval of the estimated risk ratio. On the other hand, it should be highlighted that consistent results have been shown in two large cross-sectional studies [3, 4].

\section{Conclusions}

In this population-based cohort study participants with high hs-CRP levels at baseline had an increased risk of chronic migraine.

\section{Acknowledgements}

The Nord-Trøndelag Health Study (The HUNT Study) is a collaboration between HUNT Research Centre, (Faculty of Medicine and Health Sciences, NTNU, Norwegian University of Science and Technology), Trøndelag County Council, Central Norway Regional Health Authority, and the Norwegian Institute of Public Health.

\section{Authors' contributions}

KH: Study concept and design, collection of data, analysis and interpretation of data, writing of manuscript. LJS an JAZ: Interpretation of data, critical revision of manuscript. All authors read and approved the final manuscript.

\section{Funding}

This research received no specific grant from any funding agency in the public, commercial, or not-for-profit sectors.

\section{Availability of data and materials}

Part of the dataset supporting the conclusions of this article is available on request to the corresponding author. Some of the data are the property of HUNT Research Centre and can only be accessed through direct contact with the Research Centre.

\section{Ethics approval and consent to participate}

This study was approved by the Regional Committee for Ethics in Medical Research (2018/2428 REK midt)). The participants have given written informed consent.

Consent for publication

Not applicable.

Competing interests

None of the authors have any competing interests in the manuscript. 


\section{Author details}

'Department of Neuromedicine and Movement Science, Faculty of medicine and health sciences, Norwegian University of Science and Technology, 7489 Trondheim, Norway. ${ }^{2}$ Clinical Research Unit Central Norway, St. Olavs University Hospital, Trondheim, Norway. ${ }^{3}$ Norwegian Advisory Unit on Headaches, St. Olavs University Hospital, Trondheim, Norway. ${ }^{4}$ Department of Research and Innovation, Division of Clinical Neuroscience, Oslo University Hospital, Oslo, Norway. ${ }^{5}$ Institute of Clinical Medicine, University of Oslo, Oslo, Norway.

Received: 21 April 2020 Accepted: 1 June 2020

Published online: 05 June 2020

\section{References}

1. Andreou AP, Edvinsson L (2019) Mechanisms of migraine as a chronic evolutive condition. J Headache Pain 20:117

2. Lippi G, Mattiuzzi C, Cervellin G (2014) C-reactive protein and migraine. Facts or speculations? Clin Chem Lab Med 52:1265-1272

3. Hagen K, Hopstock L, Eggen A, Mathiesen E, Nilsen KB (2019) Does insomnia modify the association between c-reactive protein and migraine? The Tromsø study 2015-2016. Cephalalgia 39:1022-1029

4. Hagen K, Stovner LJ, Nilsen KB, Kristoffersen ES, Winsvold BS (2019) The impact of C-reactive protein levels on headache frequency in the HUNT study 2006-2008. BMC Neurol 19:229

5. Krokstad S, Langhammer A, Hveem K, Holmen TL, Midthjell K, Stene TR et al (2013) Cohort profile: the HUNT study, Norway. Int J Epidemiol 42:968-977

6. Hagen K, Stovner LJ, Zwart JA (2020) Time trends of major headache diagnoses and predictive factors. Data from three Nord-Trøndelag health surveys. J Headache Pain 21:24

7. Kushner I, Rzewnicki D, Samols D (2006) What does minor elevation of Creactive protein signify? Am J Med 119:17-28

8. Headache Classification Committee of the International Headache Society (IHS) (2018) The international classification of headache disorders (IHS), 3rd edition. Cephalalgia 38:1-211

9. Hagen K, Zwart JA, Aamodt AH, Nilsen KB, Bråthen G, Helde G et al (2010) The validity of questionnaire-based diagnoses: the third Nord-Trøndelag health study 2006-2008. J Headache Pain 11:67-73

10. Hagen K, Åsberg AN, Uhlig BL, Tronvik E, Brenner E, Sand T (2019) HUNT4: the validity of questionnaire-based diagnoses. J Headache Pain 20:70

11. Hagen K, Åsberg A, Stovner L, Linde M, Zwart JA, Heuch I (2018) Lifestyle factors and risk of migraine and tension-type headache. Follow-up data from the Nord-Trøndelag health surveys 1995-97 and 2006-2008. Cephalalgia 38:1919-1926

12. Macy EM, Hayes TE, Tracy RP (1997) Variability in the measurement of Creactive protein in healthy subjects: implications for reference intervals and epidemiological applications. Clin Chem 43:52-58

13. Hagen K, Stovner LJ, Zwart JA (2007) Potentials and pitfalls in analytical headache epidemiological studies. Lessons to be learned from the HeadHUNT study. Cephalalgia 27:403-413

14. Rockett FC, Perla Ada S, Perry ID, Chaves ML (2013) Cardiovascular disease risk in women with migraine. J Headache Pain 14:75

15. Avci AY, Lakadamyali H, Arikan S, Benli US, Kilinc M (2015) High sensitivity Creactive protein and cerebral white matter hyperintensities on magnetic resonance imaging in migraine patients. J Headache Pain 16:9

16. Lyngberg AC, Rasmussen BK, Jørgensen T, Jensen R (2005) Incidence of primary headache: a Danish epidemiologic follow-up study. Am J Epidemiol 161:1066-1073

17. Lyngberg AC, Rasmussen BK, Jørgensen T, Jensen R (2005) Has the prevalence of migraine and tension-type headache changed over a 12-year period? A Danish population survey. Eur J Epidemiol 20:243-249

18. Schistad El, Stubhaug A, Furberg AS, Engdahl BL, Nielsen CS (2017) Creactive protein and cold-pressor tolerance in the general population: the Tromsø study. Pain 158:1280-1288

19. Ho KKN, Simic M, Cvancarova Småstuen $M$, de Barros Pinheiro $M$, Ferreira $\mathrm{PH}$, Bakke Johnsen $\mathrm{M}$ et al (2019). The association between insomnia, C- reactive protein, and chronic low back pain: cross-sectional analysis of the HUNT study, Norway Scand J Pain. [Epub ahead of print]

20. Schisterman EF, Cole SR, Platt RW (2009) Overadjustment bias and unnecessary adjustment in epidemiologic studies. Epidemiology 20:488-495

\section{Publisher's Note}

Springer Nature remains neutral with regard to jurisdictional claims in published maps and institutional affiliations.

\section{Ready to submit your research? Choose BMC and benefit from:}

- fast, convenient online submission

- thorough peer review by experienced researchers in your field

- rapid publication on acceptance

- support for research data, including large and complex data types

- gold Open Access which fosters wider collaboration and increased citations

- maximum visibility for your research: over $100 \mathrm{M}$ website views per year

At BMC, research is always in progress.

Learn more biomedcentral.com/submissions 